\title{
The Convergence Theory on ICT, Society and Human Beings - towards the Good ICT society
}

\author{
Gunilla Bradley
}

School of ICT, Royal Institute of Technology, Stockholm, gbradley@kth.se

\begin{abstract}
The convergence model illustrates ongoing changes in the Net Society. However the theoretical model goes back and synthesises the theoretical framework in research on psychosocial work environment and computerization. Interdisciplinary research programs were initiated by the author in the 70th and then analyzed changes in society related to various periods in "the history" of ICT. The description of the convergence model is structured with reference to the concepts Globalization, ICT, Life Environment, Life Role, Effects on Humans. Both Convergence and Interactions are important features in the model. There are four levels of analysis - individual, organisational, community, and societal.
\end{abstract}

Keywords: Theory, ICT society, Convergence, Psychosocial, Human Beings

Acknowledgement: Acknowledgement text acknowledgement text acknowledgement text acknowledgement text acknowledgement text acknowledgement text acknowledgement text acknowledgement text acknowledgement text acknowledgement text acknowledgement text acknowledgement text

\section{Introduction}

Since 2000 I have been involved in IADIS "International Association for Developing the Information Society" - first as key note speaker at the "E-society" conference in the small Spanish medieval city Avila, one year later at the IADIS conference on "Web based community" in Algarve at the golden south coast of Portugal. Both events gave me very positive experiences - the content, the quality, and the people. So when Professor Pedro Isaias invited me to design a conference that dealt with my main research area over the years, I accepted with pleasure. It was easy to decide the title of the conference - it would address interdisciplinary research and development on the interplay between ICT, Society, and Human Beings. "Human Beings" is an import word here. Why use words as "agents" in stead of "humans" and/or "people"? Many conferences world wide are not paying much attention to the fact that all technology is for humans and should facilitate and improve our wellbeing and quality of life.

The second IADIS conference in this field took place in Algarve in June 2009 during the holy Swedish Midsummar festival and it became even more successful than the first one in Amsterdam 2008. Professor Wolfgang Hofkirchner organized a special panel entitled "Approaches towards ICTs and Society - Theories and Methodologies" and wanted me to participate in the panel. Since I served as program chair and organizer of the conference I limited myself to give an oral contribution. Afterwards we agreed that I should contribute with the main power points summarizing my presentation for this special issue of TripleC journal. An 
important source for this article is also a recent book chapter in a Festschrift for Professor Holger Luzcak (Schlick 2009).

\section{The convergence Theory on ICT, Society, and Human Beings}

\subsection{Convergence Theory}

The Convergence Model could be seen as a synthesis or aggregation of my initial theoretical models. I have often given the convergence model the subtitle "ICT and the Psychosocial Life Environment". The convergence model is primarily a graphical illustration of ongoing changes in the Net Society. However the theoretical model goes back and synthesises the theoretical framework in my research on psychosocial work environment and computerization, with roots back to the $1970^{\text {th }}$ research and research programs during various phases of the history of computerization. Hence this article starts at the end and ends at the start.

The convergence model is presented in detail in my book "Social and Community Informatics - Humans on the Net" (Bradley 2006). Some comments to the model in figure 1 will follow and the description is structured with reference to concepts in the outer circle in the figure: Globalization, ICT, Life Environment, Life Role, Effects on Humans (to the utmost right)

The present Network period is very much based on the convergence and integration of processes on various levels of analysis. Converging circles graphically reflect the ongoing processes. The converging technologies are: computer technology, tele-technology and media technology. The convergence process is enforced all the time by smaller, cheaper, and more powerful technical components. ICT is increasingly being used in almost every activity and embedded in more and more things (ubiquitous computing).

Both Convergence and Interactions are important features in the model. Convergence here means a move towards a common content. Interaction means that technology interacts with the social world with values and beliefs. There is also an ongoing interaction between the "clusters of circles". There are four levels of analysis - individual, organisational, communital, and societal.

In the following, the main constituents of the convergence theory in figure 1 are presented.

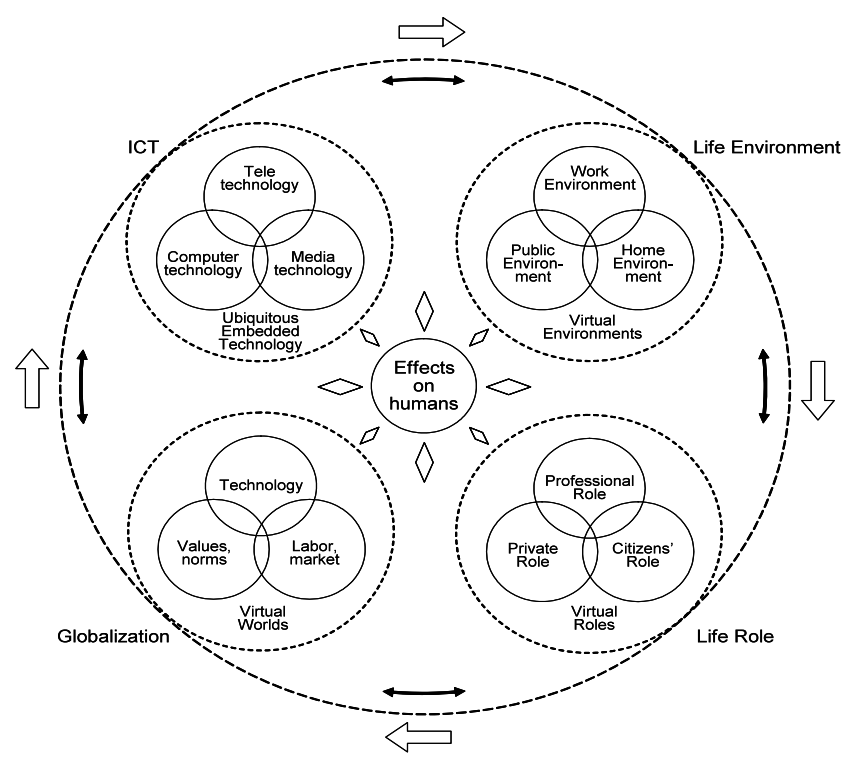

Figure 1: Convergence Model on ICT and Psychosocial Life Environment (Bradley 2005, 2006) 
- Globalisation: A convergence is occurring between Technology, Norms/Values (Economy) and Labour Market and is entitled Globalisation. Values related to the economic system is a strong driver. The geographical span is changing. At present our work life is mainly based on national and international trade which will become more global. Electronic commerce and electronic market places are creating a strong change factor behind the structure of work life. The geographical space in the future is both global and beyond - including applications of virtual reality (VR). The dotted line around the converging circles illustrates the Virtual Worlds.

- ICT: A convergence of computer technology, telecommunication technology and media technology is occurring to become what is defined as ICT. Knowledge companies and knowledge workers are increasing. In these organisations knowledge is managed in new ways. In the $21^{\text {st }}$ Century there are multiple communication channels - word of mouth, writing, audio visual, and electronic. Meta channels, e.g. meta media of virtual reality (VR) and controlled reality environments (environments that we manipulate and manage in VR) are increasingly applied. The dotted line around the three circles illustrates the embedded, (pervasive, ubiquitous) technology.

- Life Environment: Work Environment, Home Environment and Public Environment are converging to a Life Environment, where the work and public environments move into our homes. A new emphasis on certain dimensions in the present psychosocial environment as well as identifying quite new dimensions in the psychosocial environment is important. We have to be open for unforeseen implications. The dotted line around the three circles illustrates the Virtual Environments. In Media research the term "environment" is often replaced by "spheres" and you talk about work sphere, public sphere, and private sphere. Also the concept of "landscape" is coming into use.

- Life Role: The Professional Role, The Private Role, and Citizen's Role converge to become a Life Role. Role and role formation are central concepts in social psychology and represents a level between structures and the individual. A "role" appears where psychology and sociology are meeting and social psychology emphasizes the interaction between the levels of analysis. In democracies the individual can influence and form his/her role/roles and is not solely a victim for structures.

- Effects on Humans: In figure 1 "Effects on Humans" is represented by the circle in the middle with arrows pointing in two opposite directions as a flower or a compass card, which illustrate interactions. The individual is affected by ICT, the Life Environment with its three sub environments, the Life Role with its three sub roles, and Globalisation with its three components of values, technology and labour market. However, the individual can also influence the technology, the environment, and his/her own roles and phenomena on the organisational and societal level and the new virtual reality. Complexity characterizes the society and its structures, which is illustrated by the interaction of the clusters of circles in the model. It is also mirrored by the fact that effects on the individual become more multi- faceted and complex. The way humans handle his/her situation can roughly be categorized as either active or passive reactions.

- Virtual Reality (VR) as a summarizing concept is illustrated by the four circles marked with dotted lines, surrounding the four clusters of converging circles. These circles reflect our participation in cyberspace on various levels.

- To the lower left part in figure 1 we could talk about Virtual Worlds on the global level.

- Within the concept of ICT the phase by applied Embedded (Pervasive, Ubiquitous) technology make the technology less perceivable to the individual and to society as a whole. 
- Virtual Environments in the upper right part of figure 1 has been a common concept for some time. Other names are on line communities and virtual communities.

- Virtual Human Roles in the lower right part could in a more extreme form, be expressed by another person/personality that people take on e $g$ avatars. Regarding the citizens role is VR is a strong factor that is reshaping the power balance between the present authorities and the grass routs and is strengthening the civil society. The main tools are internet and web technologies, mobile phones and new software applications within what is entitled as social media technology.

The important key processes in the model are Convergence; Interaction; Participation; Psychosocial processes; Globalization; Democratic processes. The thin double-directed arrows in the outer part of the big circle represent interaction between the clusters of circles and the broad arrows represent the main direction for the movement and the process described in the circle model. The main direction is emphasised by an increasing rate of change in society. Transferred to actions: We can in our professional role, private role and citizen's role influence our life environment on various levels of analyses, but an awareness of the speed of change is required.

Closely connected to the convergence model is ongoing changes in the home and home environment, where the professional role, private role, citizen's role, and learning role are converging. During the last few years we have studied changes in society and human behavioural patterns in the use of ICT in homes and home environments in the USA, South East Asia (Singapore, Malaysia) and Japan (Bradley, Linda et al 2000, Bradley, L. and Bradley, G. 2001, Bradley L. 2005, Danielsson 2007). A general trend is that in the home many human roles and many environments are converging to one life role and one life environment. The home is moving towards encompassing also a virtual space as well as physical. Driving forces are converging and embedded technologies. The home could be regarded as communication sphere encompassing an extended family centre; a care centre; a multimedia centre; a centre for democratic dialogue; a market place; a learning centre; an entertainment centre. Danielsson (2007) applied the convergence model in her thesis "Relationships Between Information Communication Technology and Psychosocial Life Environment. Students and Young Urban Knowledge Workers in the ICT". Jansson (2005) applied the convergence theory in the new organizational structures, presented in her thesis on "Working Together when Being Apart. An analysis of distributed Collaborative Work through ICT from Psychosocial and Organisational Perspective".

Definition and then operationalisation of theoretical concepts are permanent tasks for research in the field, since the basic structures are changing and new ones are appearing and identified. I exemplify this process with a figure (figure 2) from a project in the $80^{\text {th }}$ and would like to refer to certain chapters in my book "Social and Community Informatics - Humans on the Net" where the whole process of the interaction between theory and empirical work is presented with special focus on studying the introduction, development, and use of ICT. Theories, methods, and results from my research were for many years published in the Swedish language. 'Psychosocial Work Environment and Computers' was the title of my first international book (Bradley 1986 in Swedish, 1989 in English). The research programs I initiated and led dealt with four main historical periods of computerisation and ICT, from the main frame period with the use of batch processing systems to on line period and use of display terminals and over to micro-computerization at the appearance of microchips, over to the net period when the communication technologies played a dominant role at the convergence of technologies. 


\subsection{Convergence and Allocation Issues}

Despite the observable process of convergence in the ICT society there are also countermovements - a process of divergence. Regions, nations and subgroups in the world work and strive towards separation, self-government, autonomy and sometimes self selected isolation. Related to this phenomenon is the allocation issue in a broad sense. Throughout computerisation it has been possible to make huge profit. The question of allocating the profits should have been a key issue at an early stage in policy programs. However not until recently, even if the global economy could be foreseen, has the allocation issue come into focus for actions both at the national and global level, dealing with the balance between:

- work and leisure time

- paid citizens' services versus unpaid

- production and reproduction

- cities and rural areas

- profit between:

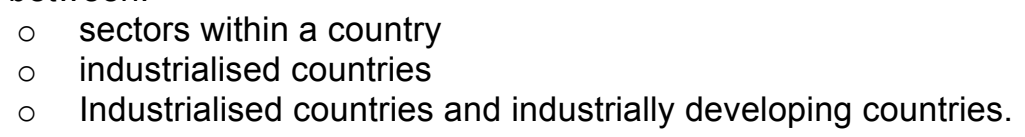

The often used "Digital divide" is an analytical term whereas "Allocation issue" (allocation of resources) is a political term. The potential of balancing deep divides in resources is inherent in ICT, but action plans are needed - short term and long term. The risk is otherwise increasing for conflicts and weaponed aggression.

\subsection{Convergence Model and the Effects on Human Beings}

Regarding "Effects on Humans" in figure 1 we can conclude that the use of ICT has changed the following human qualities so far: identity and self-perception; social competence; creativity; integrity; trust; dependency, and vulnerability. For example the identity of humans has acquired new and additional bases through the participation in various virtual and online communities. Each of those qualities could either be strengthened or weakened. In stress-theoretical terms we often talk about the importance of balance. ICT is contributing to a balance between for example: emotional- rational components of life; female - male aspects; involvement alienation.

Research shows that an accelerated tempo is occurring in the industrialised world. Certain "ICT stress" is related to an increased dependency on computers and networks and an increased expectancy that these technologies are functioning well. Stress phenomena in the Internet world are information overload, contact overload, demands for availability, lack of organisational filters, and difficulty in separating "noise" from essentials, changing level of expectations and an altered perception of time and space in general. Tasks, roles and environments that expose people to one of the two poles of over stimulation and under stimulation should be avoided in our society due to: the risk of stress (the individual level); the risk of a fragmented labour force (group/organisation levels); the risk for a digital divide in nation states; the risk of marginalisation and exclusion from the mainstream of society (individual, group and societal levels) (Bradley 1979; 1989).

The individual level needs more attention with respect to interaction between ICT - Society Individual. There are both positive and negative impacts on the Individual. In the present flexible network organisations too much responsibility is put on the individual who loses permanent employment. The so called "peripheral work force", often "knowledge workers" have to manage his/her competence development and market him/her, when they as individuals are exposed to a competitive world market. 
This pattern could be seen as freedom from paid work in a traditional sense and freedom to choose your life. However, we all need a basic security as employees and citizens and there is a need for balance between a strong society and strong individuals. Most people are not "strong" throughout life and we need to think in terms of sustainability both regarding physical and social environment and thus sustainable human beings. The increasing number of courses in mindfulness, preventive stress, cognitive behaviour therapy, provide sources for reflection.

\section{From Theory to Actions}

During the last few years a key question has been formulated by international bodies and organisations as to how the Human Being and her social and societal environment can be kept in the centre and how to build up an "Information Society for All" (UNESCO, 2002), (e-Europe, 2002) when developing our more and more complex ICT (Information and Communication Technology) systems, including their complex contexts. Sustainability is sometimes used as the main criteria for a Good Information and Communication Society (Bichler, Bradley, Hofkirchner 2009, Jansson \& Bradley 2004). Research on ICT, society and the individual and analyses of the associated psychosocial processes have led forward to address goals and visions of the ICT society. They could be formulated as policy statements and with positive formulations of goals to be reached. ICT should contribute to goals such as (Bradley 2001):

- Information access for all

- Wellbeing and quality of life for all

- Enrichment in the social contact between people

- Integration and respect for diversity

- Greater autonomy for the individual

- Prevention of various kinds of overload and stress

- Deepening of true human qualities

- Deepening and broadening of democracy

- E-cooperation and peace

- Sustainability in a broad sense, including the environment, economy, and human side.

Internationally the first official statements of goals for the ICT society were formulated at the World IT Forum (WITFOR 2003). The so called Vilnius Declaration brought forward goals which had a great implication for the involvement of the developing countries e. g. bridging the digital divide between rich and poor in the world; urban and rural societies; men and women; different generations. Another main concern was reducing poverty through the use of education and Information and Communications Technology (ICT).

Sustainability and the use of ICT are closely connected. Sustainability can be defined as a convergence between environmental, economical, social and cultural sustainability. Important perspectives are system perspective, holism, human aspects, bottom-up, common good, and equality. Many of these concepts are overlapping and possible to analyse from various angles. Action-oriented and value-oriented research is coming to the fore. Social Informatics is highlighting a field of research, practice and education with accelerated speed of change and complexity as well as urgency. Social Informatics is more and more being a mandatory part in education and training in ICT-related disciplines. There is a need for a much stronger support internationally for cross-disciplinary, cross-cultural and action-oriented research on the topic ICT for the deepening and enriching of Humane and Societal qualities.

Official bodies on the international and national level e. g WSIS (World Summit on the Information Society) and national ICT programs are actors as we move to an ICT society on a global scale. Various components of ICT such as internet, web, and blogs should be used for dialogue between cultures, to increase mutual understanding, and enrich us all. How can 
Human Rights be more deeply understood, exemplified and applied in the ICT society? In 2006 the United Nations started to review the issue of Human Rights - the use of ICT globally has made the need of this review clear. Europe has a similar agenda.

Visions are shared about wellbeing, democracy and quality of life for all as well as social, economical and ecological sustainability - possible to illustrate with the convergence of circles in figure 1. We can all be actors in this process, researchers, IT professionals, NGOs, and an Individual.

\section{Summary}

Four figures from my presentation at the IADIS conference on "ICT, Society and Human Beings" are used as a summary of the convergence theory on "ICT, Society and Human Beings". The figures are interrelated, concepts in one figure are mirrored in the other figures. I have newly observed at a very personal level when I newly got a grandchild, the convergence processes in the lives of young men and women, as well as grandmothers and grandfathers. Work Environment, Public Environment, Private Environment, Virtual Environment are converging at the fulfilment of the various roles in a modern society.

The industrialized world has got a highly effective production both of services and goods through the long rationalization process facilitated by ICT. For the service side most tasks have been moved to unpaid work of the customers. The visions and goals for the Good ICT society for Human Beings need a stronger recognition and action strategies on all levels of society including the global level. A quote from my own home page:

We now have a whole new chance to explore the human side of societal change taking advantage of technology to shape a good and balanced life. Let us use this opportunity to redesign society towards peace, democracy and welfare for all...those who develop, introduce and use technology promoting peace, a deepening of democracy, welfare and quality of life for all will be the winners" (Bradley 2001, p. 21)

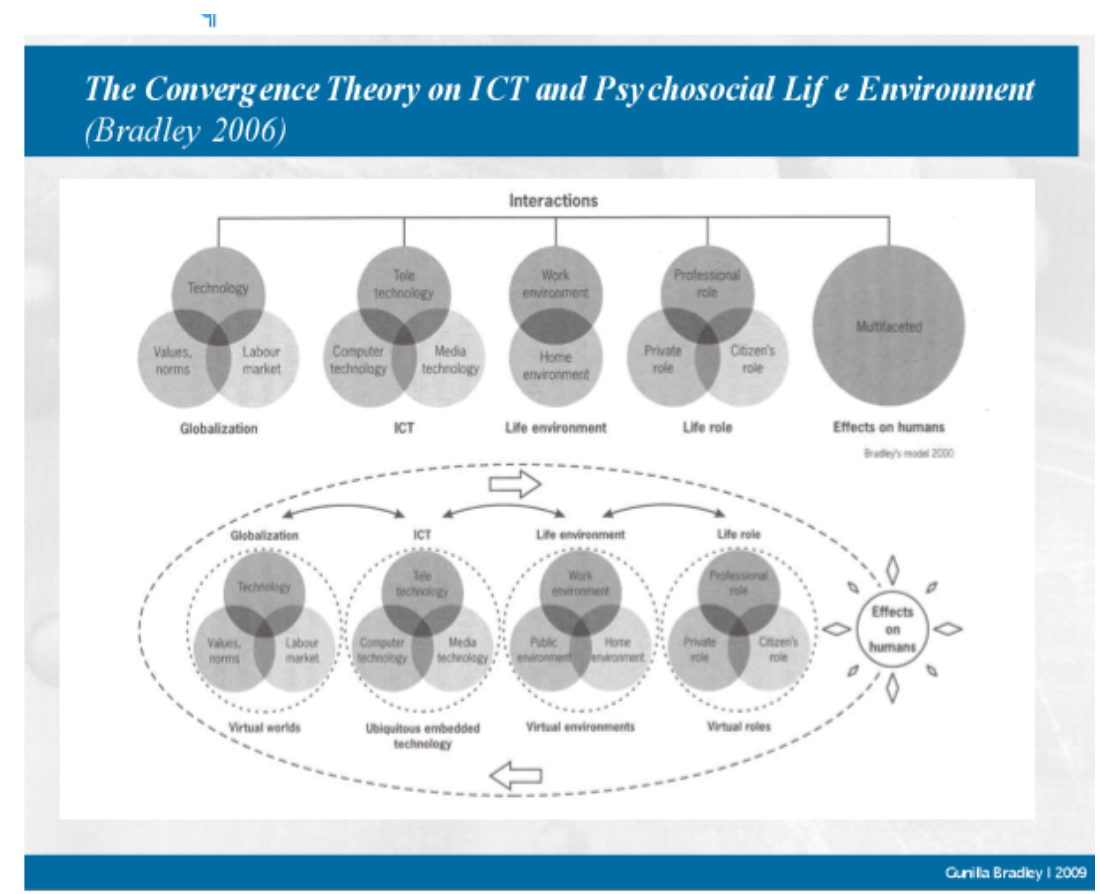

Figure 2: The convergence model. 
Crossdisciplinary research is crucial and it could be exemplified in the model saying that the following disciplines are represented starting from the left: 1. Policial Science and Economy; 2. ICT-related disciplines 3. Sociology and social anthropology 4. Social Psychology 5. Psychology.
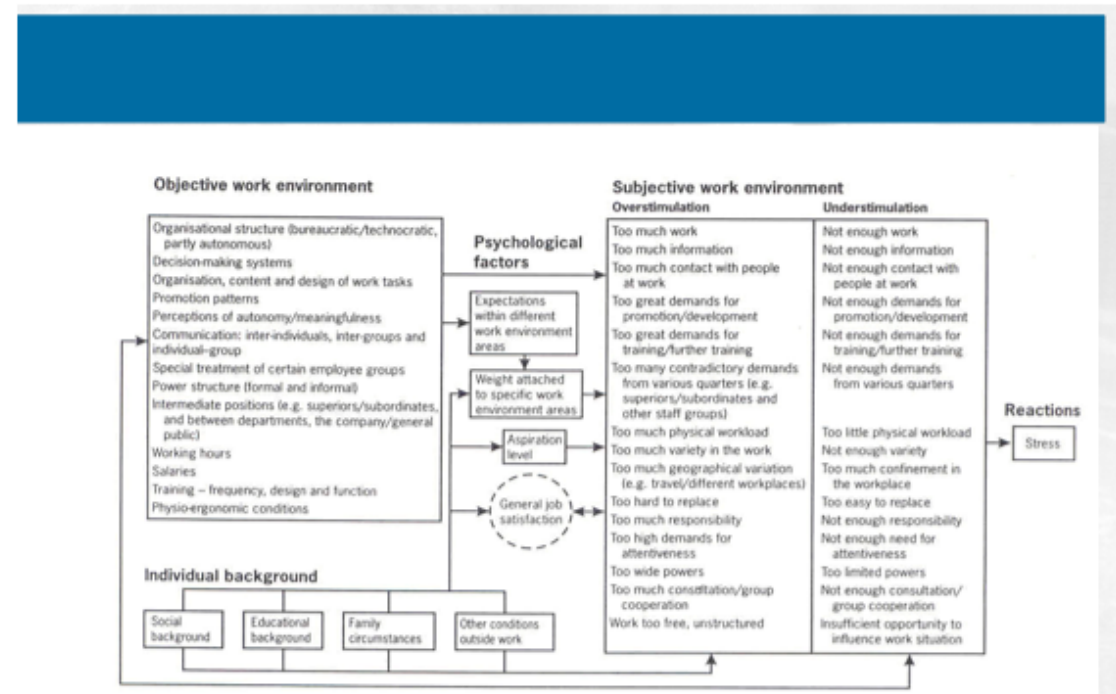

Figure 8.2 Relationship between computer technology, work environmem and stress

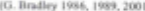

Figure 3: Theoretical concepts on ICT and Stress (Source Bradley 1989)

The model in figure 3 is an example from our studies on the relation between ICT and stress in the work place. The broad concepts in the original model in Figure 4 were defined and brought to empirical studies through various forms of methods for collecting and analysing. 


\section{Computer Technology and Work Environment}

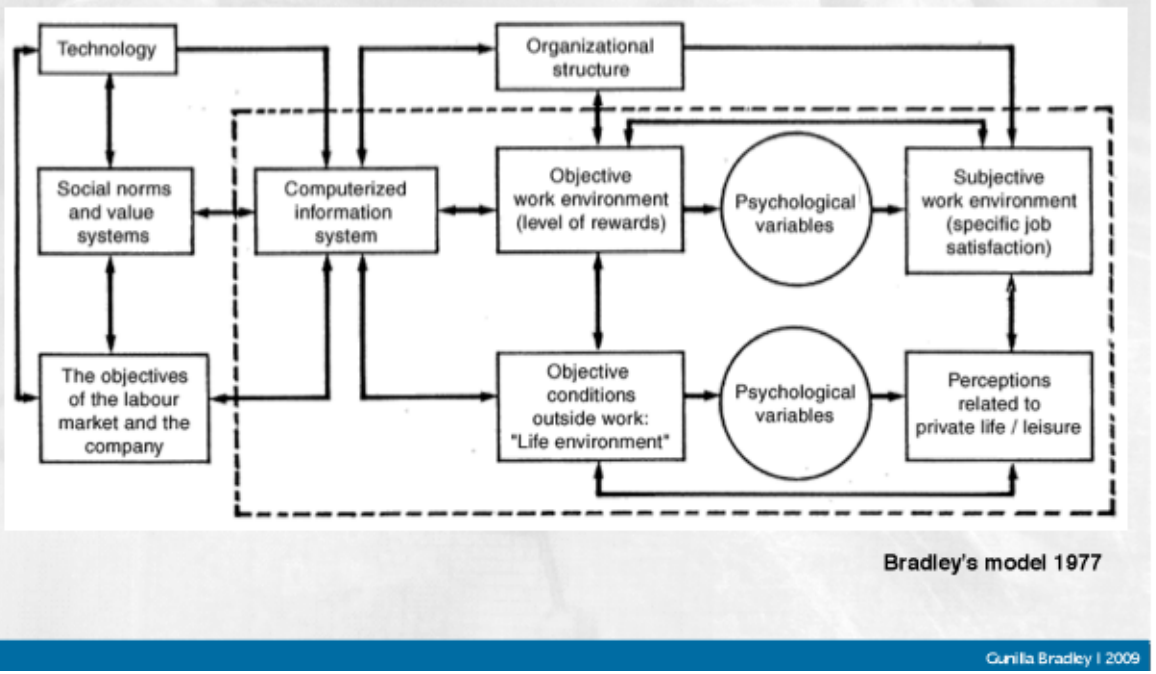

Figure 4: Computer technology and work environment (Source: Bradley 1977)

Figure 4 was the original theoretical model used in the $1970^{\text {th }}$ for applying for research funding. The main concepts were further defined and brought to empirical measures in a series of research projects. Of course the concepts in figure 4 could be updated e. g. "Computerized information system $=\mathrm{ICT}$, Organizational structure $=$ Network organisations. However the core is coming back in the convergence model in figure 1 and 2.

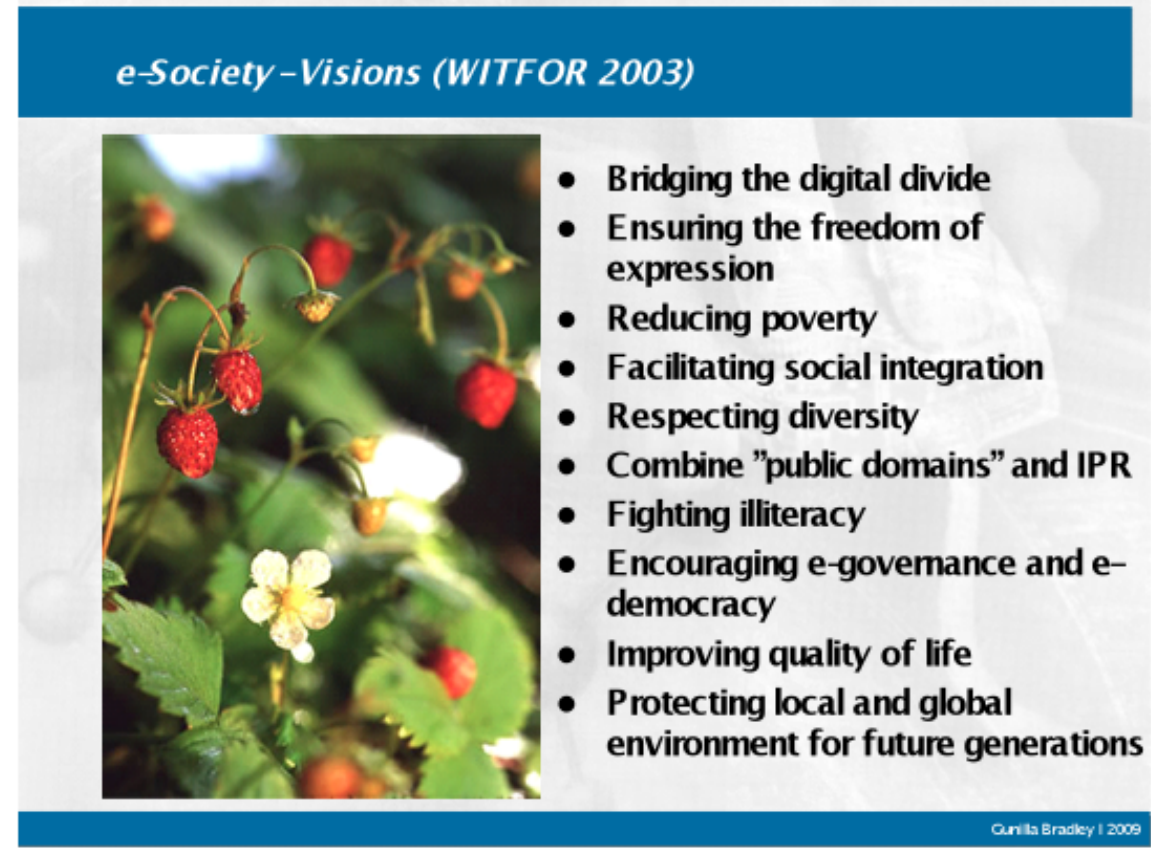

Figure 5: The Good ICT Society 
Internationally the first official statements of goals for the ICT society were formulated at the World IT Forum (WITFOR 2003). The so called Vilnius Declaration (figure 5) brought forward goals which had a great implication for the involvement of the developing countries.

\section{References}

Bichler, R.. Bradley, G. \& Hofkirchner, W. (2009). Special Issue on Sustainable Development and ICTs. Information Communication \& Society 13(1), 1-5.

Bradley, G. (1977). Datateknik, Arbetsliv och Kommunikation. (Computer Technology, Work Life, and Communication). The Swedish delegation for long term research. FRN. Stockholm: Liber.

Bradley, G. (1979). Computerization and some Psychosocial Factors in the Work Environment. In U.S. Department of Health, Education, and Welfare (Ed.): Proceedings of the conference Reducing Occupational Stress. (pp. 30-40). NIOSH Publication No. 78-140.

Bradley, G. (1986 \& 1989). Computers and the Psychosocial Work Environment. London,Philadelphia: Taylor \& Francis.

Bradley, G. (Ed.) (2001). Humans on the Net. Information and Communication Technology (ICT) Work Organisation and Human Beings. Stockholm: Prevent.

Bradley, G. (2005). The Convergence Theory on Information and Communication Technology (ICT) and the Psychosocial Life Environment - The Connected Home. In G. Salvendy, (Ed.). Proceedings of the HCl International 2005 conference, 22-27 July 2005, Las Vegas, Mahwah: Lawrence Erlbaum Associates.

Bradley, G. (2006). Social and Community Informatics - Humans on the Net. London: Routledge

Bradley, Linda. Andersson, N. \& Bradley, G. (2000). Home of the Future - Information and Communication Technology (ICT) - changes in society and human behavior patterns in the net era. FSCN Report R00-1. Mid-Sweden University.

Bradley, L. \& Bradley, G. (2001). The Home as a Virtual and Physical Space - Experiences from USA and South- East Asia. In M. Smith \& G. Salvendy (Eds). Systems, Social and Internationalization Design Aspects of Human-Computer Interaction. (pp. 81-85). Mahwah, NJ: Lawrence Erlbaum Associates.

Bradley, Linda (2005). Home of the Future Japan - Information and Communication Technology (ICT) and Changes in Society and Human Patterns of Behavior in the Network Era. Stockholm: Royal Institute of Technology (KTH).

Danielsson, U. (2007). Relationships Between Information Communication Technology and Psychosocial Life Environment. Students and Young Urban Knowledge Workers in the ICT-Era. Mid Sweden Doctoral Thesis 41.

Jansson, E. (2005). Working Together when Being Apart. An analysis of distributed Collaborative Work through ICT from Psychosocial and Organisational Perspective. Doctoral dissertation at Department of Computer and System Sciences, IT University, Royal Institute of Technology, Stockholm.

Jansson, E. \& Bradley, G. (2004). Sustainability in Collaborative Network Structures - with focus on the Psychosocial Work Environment in Distributed Teams. In Proceedings of the CIRN conference on Sustainability and Technology: What does this Mean for Community Informatics, 1. (pp. 271-283). Prato, Italy, 29 September-1 October Community, 2004.

Schlick, C. M. (2009). Industrial Engineering and Ergonomics - Visions, Concepts, Methods and Tools. Festschrift in Honor of Professor Holger Luzcak. Berlin, London, New York: Springer.

\section{About the Author}

Gunilla Bradley

Gunilla Bradley is Professor Emerita in Informatics at Royal Institute of Technology (KTH) - School of ICT. 1997 - 2001 she was Professor of Informatics at Umeå University and Mid Sweden University with main task to build up research in Informatics at Mid Sweden University. She is educated as a psychologist and has a broad background in the social and behavioural sciences. Her research concerns the interplay between Information and Communication Technology (ICT), Human Beings, and Society - Social Informatics. 